\title{
Study on the influence of different magnetic and electric field-assisted storage methods on non-thermal effects of food
}

\author{
Galiya ABDILOVA ${ }^{1 *}$ (D), Anna TEREKHOVA², Maxim SHADRIN ${ }^{3}$, Nina BURAKOVSKAYA 3 , \\ Natalya FEDOSEEVA ${ }^{4}$, Marina ARTAMONOVA 5 , Alena ERMIENKO 5 , Maria SMIRNOVA ${ }^{6}$, Igor GRIGORYANTS ${ }^{2}$, \\ Ekaterina STRIGULINA ${ }^{2}$
}

\begin{abstract}
Food processing (FP) industries are dominated by thermal inputs for food preservation. Such treatments can, however, contribute to some undesirable changes in the quality attributes and nutritional value of food. Non-thermal storage processes, on the other hand, have a negligible effect on the sensory consistency and nutritional status of food. Food preservation has used food with non-thermal methods with the aim of preserving the nutritious properties and physic-chemical features of foods. In this respect, the pulsed electrical field offers an alternate option for different food items, in particular liquid food products, in order to improve the protection and maintenance of new, consistent aspects of food. Similarly, this study emphasizes the promise of pulsed electric field technology as a useful method for preserving a variety of foods, with a focus on microbial inactivation. The key goal of this research is to find out how widely nonthermal FP equipment is used. Innovative technology can be able to help strike the right balance between protection and minimum processing, as well as sufficient economic constraints and superior efficiency.
\end{abstract}

Keywords: food processing; non-thermal storage; pulsed electric field; thermal inputs.

Pratical Application: Non-thermal effects of food.

\section{Introduction}

Heating is one of the oldest methods used to process food. Safe products can be achieved using conventional thermal methods, but in terms of quality, they are subject to changes that are not pleasing to consumers today ( Zhang et al., 2019; Zhao et al., 2019; Silva et al., 2020a). Modern thermal and non-thermal processing techniques have been used for many years in the production of various industrial products. Ohmic heating is one of these technologies. In this method, heat is generated inside the food by passing through it an alternating electrical current. Like other techniques, this technology has advantages and disadvantages and has been used for many years in the processing of food products, in particular liquid food (Rifna et al., 2019; Schottroff et al., 2018). In this article, we tried to give a complete definition of ohm heating along with its history of use. Recent applications of this technology have also been investigated in various food industries (Guillén et al., 2020; Hyun \& Lee, 2020; Moreira et al., 2019; Osae et al., 2020; Silva et al., 2020b).

Heating is one of the oldest methods used to process and store food that humans have been using for many years. Secure products can be achieved with conventional processing technologies, but the product is damaged in terms of quality and value (González-Pérez et al., 2021).

Today, consumers prefer products with the least amount of processing and the most nutrients (Bhattacharjee et al., 2019). In recent years, heating techniques have made significant advances that could be made (Afshari \& Hosseini, 2014; Knorr et al., 2002; Morris et al., 2007; Pereira \& Vicente, 2010). Vega-Mercado et al. (1997) mentioned some of them, including ohmic heating, dielectric heating (including microwave heating and radiofrequency heating), and induction heating. In all these methods, heat is generated inside the food, so it is very efficient and produces a lot of energy. These methods are known as modern thermal techniques. Modern heat treatment methods may be referred to as pre-or post-treatment disinfection methods (in raw food disinfection, processed food packaging, or unpacked) or as an alternative to conventional heating technology (Zhang et al., 2019). These techniques have the potential to produce safer, nutrient-rich, organoleptic food that has almost no side effects due to prolonged heating of the product. Also known as yoke heating, electrical heating, and conductive heating is a method by which the alternating electrical current passes through food

\footnotetext{
Received 11 May, 2021

Accepted 17 June, 2021

${ }^{1}$ Shakarim University of Semey, Semey, Kazakhstan

${ }^{2}$ K.G. Razumovsky Moscow State University of Technologies and Management, The First Cossack University, Moscow, Russia

${ }^{3}$ Omsk State Technical University, Omsk, Russia

${ }^{4}$ Russian State Agrarian Correspondence University, Russia

${ }^{5}$ Moscow State University of Food Production, Moscow, Russia

${ }^{6}$ St. Petersburg State University of Aerospace Instrumentation - SUAI, St. Petersburg, Russia

*Corresponding author: galiyaabdilova1986@gmail.com
} 
that has electrical resistance and generates heat deep inside the product (Tewari \& Juneja, 2008). Heating occurs in the form of the transformation of internal energy into matter. In this case, electrical energy is converted into heat energy and ultimately leads to the Joule effect.

In the nineteenth century, many inventions were made on the use of resistive heating to sterilize stationary liquid food. For the first time, ohmic heating was used to pasteurize milk. Stable acid at ambient temperature has become legal (Syed et al., 2017). After that, ohm heating was widely used in Europe, the United States, and Japan. Due to the uniform production of heat and, consequently, the uniform distribution of heat in the product, in particular in liquid food, the United States Agricultural Jihad and the Food and Drug Administration. The United States proposed the use of ohm heating technology for the pasteurization of pumpable foods, including whole pieces of fruit in syrups, juices, eggs, and milk, for aseptic packaging, and was introduced as a new and outstanding technology by the Institute for Industrial Achievements of American Food in 1996 (Stoica et al., 2013). Although ohmic liquid processing is a simple, successful, and cost-effective method, it is difficult to process solid foods, such as meat and meat products, on an industrial scale. The reason for this is the difficulty of establishing direct contact between the electrodes. The surface of the food product is solid. The uniform ohm heating in solid food is essentially dependent on the uniform distribution of electrolytes within the product (Knorr, 2003; Vega-Mercado et al., 1997).

One of the applications for ohm heating is the inactivation of germs. The thermal effect of the ohm method is the main effective mechanism for the destruction of microorganisms. Other effective mechanisms are mechanical and chemical inactivation. Mechanical inactivation is the irreversible destruction of the microbial cell membrane (Pothakamury et al., 1995; Tiwari et al., 2009). In this process, pores form in the microbial cell membrane and lead to cellular content leakage (such as amino acids, proteins, and nucleic acids). This phenomenon is known as electroporation. Chemical inactivation also leads to the death of microorganisms through the formation of free radicals and the formation of metal ions. This technology is also an effective way to inactivate bacterial spores. Of course, its efficacy depends entirely on the type of microorganism because different microbes have different thermal resistances (Pal, 2017).

The extent to which advanced non-thermal food processing (FP) systems are widely used in the United States remains unclear. New innovations that meet consumer demand for high quality would be the most important goal for food science research in the future (Gerlach et al., 2008; Lelieveld et al., 2007; Ohlsson \& Bengtsson, 2002). The study was needed to determine the most desirable non-thermal FP technology currently in use in the FP industry for the preservation of food with limited processing. The previous literature on the usage of non-thermal FP technology in the industry has been limited, as has information on whether these technologies are being promoted and financed sufficiently for potential research and growth. The reasons for modern, non-thermal FP technology innovation in the United States are not well understood, such as the factors that encourage the development of these new technologies. As a result, the research will help to identify the primary drivers of creativity.

Much study has been concentrated on the development of non-thermal technology in the previous several decades. Hydrostatic or dynamic high pressure, membrane separation techniques, pulsed electric fields (PEFs), and dense phase or high-pressure carbon dioxide are only a few of them that have been widely researched for concentration, cold pasteurization, food functionalization, and extraction. When compared to their thermal equivalents, they all allow for minimally processed food with enhanced quality features. PEF and Membranes, on the other hand, have a long history of study in the treatment of industrial wastewaters, allowing for considerable recoveries and hence waste reduction. As a result, these technologies are viewed as potential for food application development that is sustainable in the present and future. However, the research progress and outcomes gained for commercial application vary from one technology to the next, making a direct comparison of different processes impossible. The majority of non-thermal methods are presently used on a lab or prototype size, resulting in increased cost of production than large-scale industrial thermal devices. As a result, more cross-sectional research is needed to truly evaluate the true potential and limitations of non-thermal technologies for improving the effectiveness of food processing operations, as well as to identify the steps that need to be optimized to render each novel technology more efficient (Martins et al., 2021; Rocha et al., 2020; Silva et al., 2020a,b) .

The primary objective of this study was to determine how non-thermal FP equipment is commonly used. Creative technology can help achieve the ideal combination of safety and negligible processing and, at the same time, balancing adequate financial constraints and outstanding efficiency. This study also looked at the main factors why food producers choose certain FP systems, as well as the drawbacks that prevent them from using different technologies. Inventions are already under development, and studies are underway to find out how to pasteurize, decontaminate and sterilize these foods while maintaining their freshness and natural nutrients. This thesis looked at emerging developments, as well as those still underway, and at the progress of fuel technology.

\section{Material and methods}

Saving energy is so important today that researchers are constantly striving to produce energy-efficient technologies that are at the same time sustainable. Ohmic heating is one of those emerging and natural-friendly technologies that has many applications both now and in the future (Corbo et al., 2009; Cullen et al., 2012; Gerlach et al., 2008). According to the provisions of this Article, it can be concluded that ohmic heating has the capacity to produce safe products by preserving nutrients and does not, at the same time, harm the quality of the products. Fast and uniform heating of the products can be achieved by this method. This technique has both thermal and non-thermal effects on the products concerned (Cebrián et al., 2016). The success rate of this method in heating products is limited by factors such as the electrical field intensity, the electrical conductivity of the product, the rate of heat generation in the 
product, the high rate of temperature increase, the electrode material, the shape of the tank and the frequency used. On the other hand, in solid foods, the uniformity of the distribution of electrodes in the product is an important issue in terms of the speed and consistency of heat production in the product (Rocha et al., 2020). On the other hand, controlling the rate of heat production in products is a serious problem that arises as a result of changes in the electrical conductivity of each product during processing. Due to the many benefits of ohm technology, it is still difficult to use in certain industries, such as the meat and meat products industry, and researchers need to explore these issues in order to make full use of this technology in all industries. On the other hand, the production of free radicals in ohm-fired products is a very serious issue that needs to be investigated. One of the issues to be considered by researchers is the use of ohm heat in continuous food production so that processing under atmospheric and vacuum conditions (to maintain quality) is possible with a high capacity.

\subsection{High-Pressure Processing (HPP)}

High-pressure processing is one of the processes that preserve the appearance of food. This process not only makes food safer and improves its shelf life but also maintains its original quality and health characteristics (Zhang \& Mittal, 2008). High-pressure processing preserves the natural quality and freshness of food and increases the microbiological shelf life of food. This process kills parasites and bacteria, which cause disease and rot. Unlike traditional thermal processing, this technology is a non-thermal pasteurization and storage technique that does not cause any change or a slight change in the sensory and nutritional properties of the product (Considine et al., 2008). Foods processed at high pressure have a better texture, fresher taste, better appearance, and higher storage capacity than heat-processed foods. This technology has been considered to be one of the best innovations in FP in the last 50 years. This technology, known as Pascalization, is also used in scientific and commercial texts. A schematic diagram of the pressure and temperature curves of a typical high-pressure process is shown in Figure 1 (Tewari \& Juneja, 2008).

\subsection{Pulsed Electric Field Processing (PEF)}

PEF pulsed electrical fields are a non-thermal food storage method that uses short electrical pulses to inactivate microbes and have the least harmful effect on food quality characteristics (Lehmali \& Jafari, 2019). The aim of PEF technology is to provide consumers with high-quality food. In terms of food quality characteristics, PEF technology is considered superior to traditional heat treatment methods because it prevents harmful changes in the sensory and physical properties of food or significantly reduces harmful changes. A simple PEF treatment device is shown in Figure 2 (Jeyamkondan et al., 1999).

PEF technology is offered as an advantage over heat treatment for the reason that it eliminates microorganisms by better preserving the nutritional value, texture, flavor, and color of unprocessed food. PEF contains the application of high-voltage pulses to liquid or semi-solid food placed between two electrodes. Most PEF studies focused on the effects of PEF treatment on microbial inactivation in milk, dairy products, egg
Pressure.

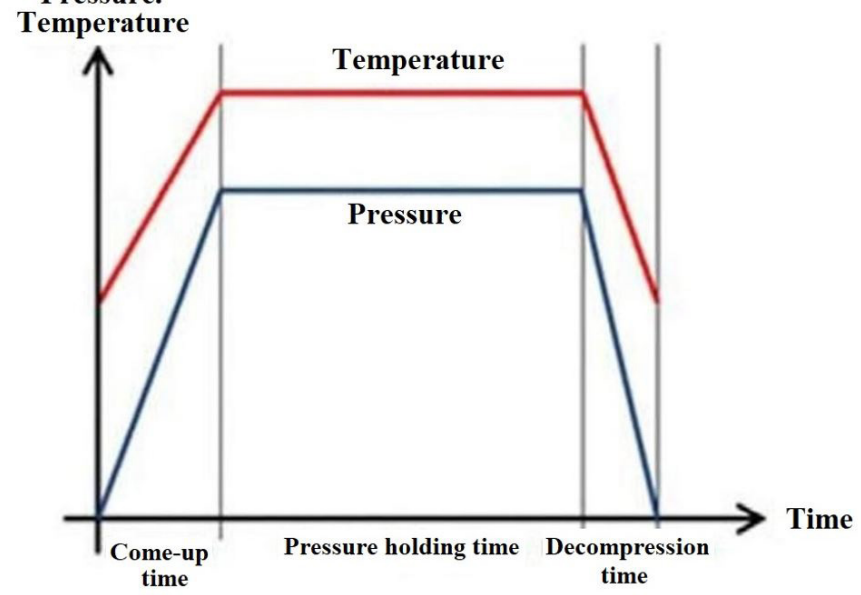

Figure 1. Pressure and temperature curves of a typical HPP.

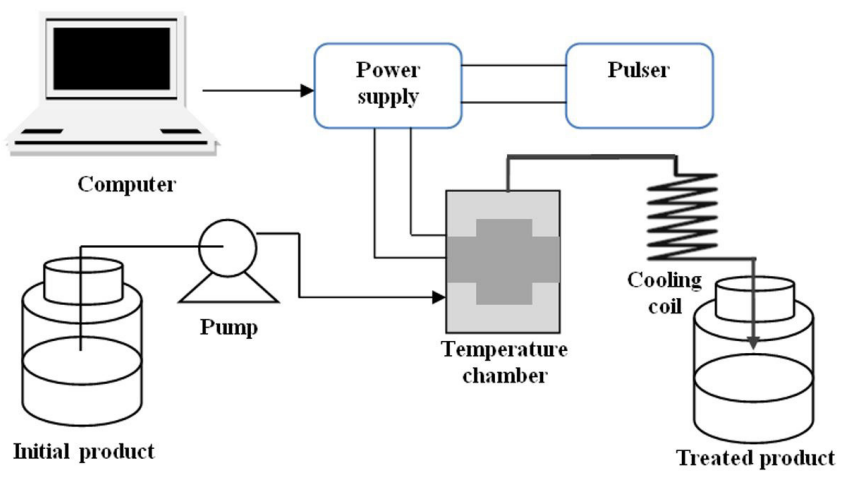

Figure 2. The diagram of a PEF.

products, fruit juices, and other liquid foods (Giner et al., 2001; Jia et al., 1999; Min et al., 2003; Wouters et al., 2001). However, while a significant amount of studies on microbial aspects of food preservation have been published by PEF, there is less information available on the impact of PEF on food ingredients and on overall quality and acceptability.

\subsection{Oscillating magnetic fields}

Traditional methods of food preservation ensure their safety but cause food damage. Non-thermal methods, on the other hand, can often preserve the nutritional value of food while at the same time reducing the microbial risk. The use of magnetic fields is one of these methods. The theories that have been proposed concerning the mechanism of interaction and interaction sites suggest that cell membranes and certain cellular organs may be the sites for receiving these waves (Shabbir et al., 2020). Fluctuations of ions and rotation of bipolar molecules, which depend on the frequency and amplitude of the induced electrical field, may lead to changes in ion diffusion within the cell and affect cell activity. Also, at these frequencies, the lactose pathways are completely open, changing the rate of growth and 
latency (Lipiec et al., 2004; Purnell et al., 2017; Rodríguez et al., 2017).

The oscillating magnetic fields are generated by electromagnets passing a fluctuating current. As compared to the earth magnetic field, which is about 5 to 100 tesla, the field strengths are exceptionally strong. Frequencies varying from 5 to $500 \mathrm{kHz}$ are used over a period of 25 microseconds to a few milliseconds. The inactivation of vegetative cells is aided by this. If the frequencies are greater than $500 \mathrm{kHz}$, the food will become heated, and the inactivation mechanism will fail. The latest research has discovered that there isn't much of an impact on spores or enzymes. Furthermore, it has the potential to promote the development of vegetative cells. When a 12.0 T oscillating magnetic field was added to milk at a frequency of $6000 \mathrm{~Hz}$, for example, cells were decreased from 25,000 to $970 \mathrm{~mL}^{-1}$.

\subsection{Food irradiation}

Irradiation may or may not be slowed down to reduce pests and the risk of foodborne disease, as well as plant spoilage or maturation or germination. Depending on the dose, sometimes or all organisms, microorganisms are destroyed by existing energies and viruses, slowed down, or unable to reproduce. If bacteria are present, most foods will be affected as they reduce active germs by a significant increase, so do not sterilize other germs in the product (Ihsanullah \& Rashid, 2017; Indiarto \& Qonit, 2020). Irradiation cannot restore damaged or overripe food. If this food is processed by irradiation, more spoilage will stop, and if it slows down, but the irradiation will not cause the food to lose its color or taste, color or taste.

Irradiation causes your speed to eat the enzymes that are changing. By eliminating spoilage organisms and slowing down germination (e.g., potatoes, onions, and garlic), irradiation is applied to reduce nutrients that are poor between harvesting and final usage. Stable products are produced on the shelf with irradiated food in sealed packaging because irradiation reduces spoilage, and the packaging of the new product makes the final product. Stimulate foods that normally require higher amounts of irradiation if you are sterilizing (Roberts, 2014). It is useful for astronauts at risk of infection in the hospital, as well as for situations where proper food storage is not possible, such as suede.

Like re-trade protection, new crops are selected for new habitats and can be shifted to increasing pressure to produce agricultural products, and the environment is significant. In order to reduce this threat and free trade at quarantine borders, food is irradiated using a technique called health irradiation. Irradiation of healthy plants with a low-dose therapeutic product (less than $1000 \mathrm{~g}$ ) sterilizes reproduction (Molins, 2001). Doses required for pest control are not used due to an effect on appearance or taste or are not acceptable for freshly supplied products. The radioisotopes cobalt- 60 and cesium-137, which are formed by neutron bombardment of cobalt- 59 and as a nuclear source byproduct, respectively, emit gamma irradiation. Since cobalt-60 is water-insoluble, it is the most popular source of gamma rays for food irradiation in industrial-scale facilities since it poses no chance of environmental pollution from leakage into water systems (Figure 3) (Diehl, 2002).

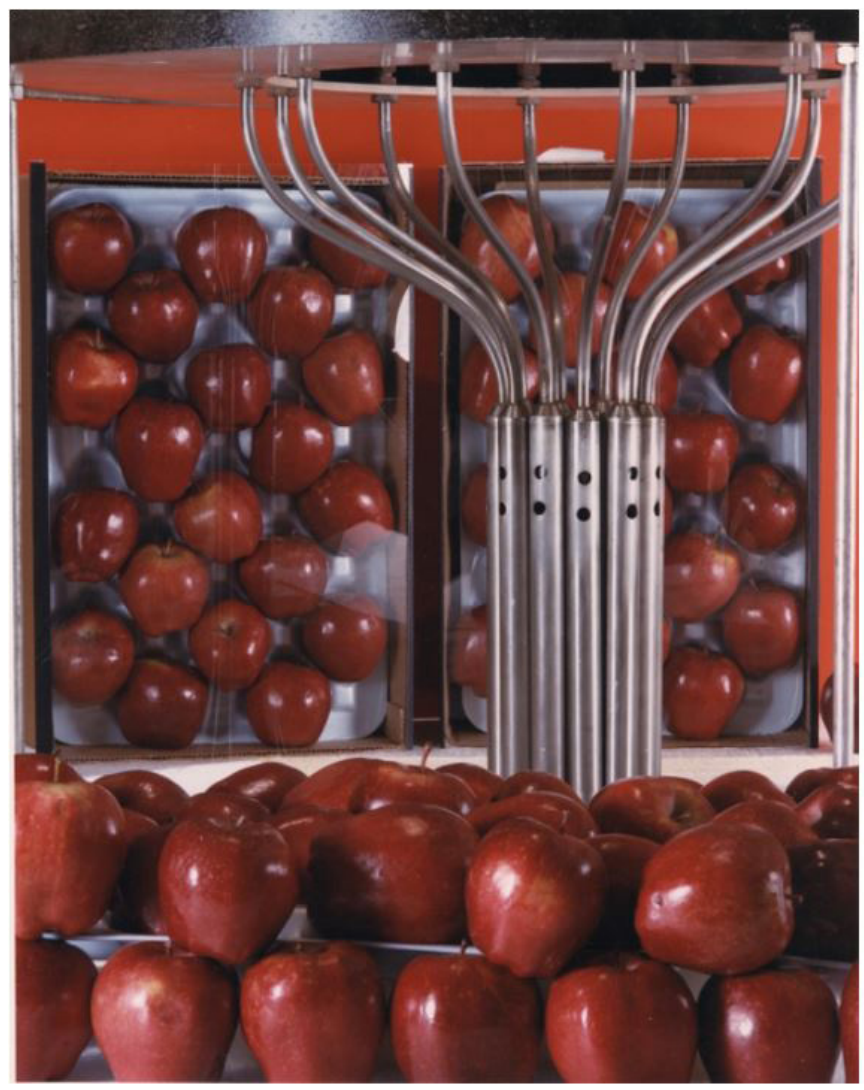

Figure 3. The Cobalt-60 irradiation plant is used to assess the efficacy of irradiation as a food protection instrument.

\section{Results and discussion}

Famine and hunger have been and continue to be some of the greatest and most important aspects of human life. One of the world's major concerns is providing healthy food to feed the world's growing population. Sadly, millions of food products are lost each year due to a variety of factors such as microbial activity, chemical and enzymatic spoilage, and environmental factors, necessitating a constant fight to keep these substances from being lost. Food packaging and protection have played a significant role in this fight. The use of various coatings for food packaging has grown into a huge industry, and the number of agricultural and food industry products available without cover and reliant on the consumer market is steadily decreasing. The use of packaged materials has gained a special place among people as a result of the growth and transformation of consumer culture. Although the packaging is primarily used to protect food from external factors, it is also used to extend shelf life. However, the link between the food inside the package and the quality of the product cannot be closed solely by packaging. The distance between the factory's production line and the consumer's table also preserves and instills a unique culture. Packaging has evolved from simple technology to a combination of art and science, and it has gained acceptance in the scientific community, to the point where factory-produced product packaging, and even certain parts of it, is now a requirement. Committed. Obviously, environmental concerns have been a major consideration in order 
to make the best use of this valuable industry while avoiding harm to human life.

Producing healthy and safe food is one of the basic needs of consumers. In addition to improving shelf life, the use of non-thermal methods to preserve food also maintains the quality of food. Food and beverage irradiation is one of the new technologies for dealing with the pollution that is spreading day by day. On the other hand, some researchers and experts doubt the usefulness and innocence of this method, and some consider it dangerous. Food irradiation is a cold process that makes food healthier. It is the process by which food and other consumer products are exposed to $\mathrm{x}$-rays, gamma rays, and electrons after surgery to kill harmful bacteria and parasites, delay spore germination, and increase food shelf life. It's high voltage. Radiation has little effect on food compounds in some cases. The temperature of the food during the non-thermal process is lower than the temperatures commonly used in thermal processes. Consequently, the reduction in quality resulting from the use of high temperatures in non-thermal processes is minimized. Vitamins, essential nutrients, and flavor enhancers are expected to remain unchanged or to be minimally altered during nonthermal processes. In addition, non-thermal processes require less energy than thermal processes.

Food can be processed using non-thermal methods such as high hydrostatic pressure, pulsed electrical fields, intense light pulses, radiation, chemicals, biochemicals.

\subsection{Application of HPP}

Pressure vessels which can withstand high pressures are used in the metal and ceramic industries. The food industry, of course, needs equipment that can withstand much higher pressures, up to about 4,000 atmospheres. High pressure may be produced in the following ways:

1) Direct compression by pressing the pressure transfer material in the piston, the end diameter of which is small. The end of the piston diameter is moved by a low-pressure pump. Compaction is very fast in this method, but the limitations of high-pressure dynamic communication between the piston and the inner surface of the tank make it difficult to apply this method in semi-industrial and laboratory systems.

2) In indirect compression, a high-pressure intensifier is used to transfer the material of the pressure conveyor from the tank to the closed tank under high pressure until the pressure reaches the desired value. In most industrial isostatic pressure systems, the indirect compression method is used.

3) The temperature pressure of the carrier material increases, expands and a lot of pressure is produced by heating. Heating of the pressure conveyor material is therefore carried out when high pressure and high temperature are used at the same time. Precise temperature control is required in this method for the entire internal volume of the pressure vessel.

\subsection{Application of PEFs}

For the sanitization of liquid food, an electrical field with short pulses and a time scale between microseconds and milliseconds is used. Food can be processed in this way under environmental conditions or at low temperatures (chilled). In order to minimize thermal processes using pulsed electrical fields, food is processed in a short time and with low energy consumption. Heat can also be generated in FP with the help of magnetic fields. Usually, there is a device inside the system to cool the reaction chamber. The reaction chamber is one of the most important and complex components of this system. To date, different types of fixed and continuous enclosures have been designed. Although thermal and electrical pasteurization methods inactivate microorganisms, the quality of the heat pasteurized milk is lower than that of the electrical method (in terms of maintaining natural freshness).

Gram-positive bacteria and germ cells are more resistant to PEF than gram-negative bacteria, and the yeast is more susceptible to bacteria. Growth cells are more exposed to PEF than to spores. As with the HPP method, the functionality of PEF increases with other methods.

\subsection{Application of irradiation}

Food irradiation is a "cold" food preservation process that has been widely studied over the last 45 years. While having beneficial results, this method does not produce toxic or radioactive compounds in the food. The benefits of this method include increasing the shelf life of root crops, disinfecting spices, fruits, and grains, reducing spoilage microorganisms, decaying fruit ripening, improving the sensory properties of food, and destroying or reducing the inevitable pathogenic microorganisms. Special mention of raw food contaminants of animal origin.

\section{Advantages and limitations of irradiation}

Food irradiation, like other methods of preservation, has its advantages and limitations, but the advantages and disadvantages are less than those indicated by its supporters and critics.

Additional research has been carried out on this method and, according to it, FP using ionizing radiation has the following advantages:

- Maintains food quality constant over different periods of time.

- No toxic residues are left in food.

- The nutritional value of the food is maintained.

- Controls the ripening, aging, and germination of fresh fruit and vegetables.

- The sensory quality of food, especially compared to other methods, is better maintained.

- It is also used for packaged and frozen food.

- Makes food free from pathogenic bacteria, yeasts, moulds, and insects.

The list of explanations why respondents preferred nonthermal FP technologies is seen in Table 1. The primary incentive for businesses to use non-thermal FP technology was to enhance nutritional and sensory efficiency (65.87\%). 
Table 1. The reasons for selecting non-thermal FP technologies by companies $(\mathrm{N}=211)$.

\begin{tabular}{lcc}
\hline \multicolumn{1}{c}{ Description } & Percent & Frequency \\
\hline Better nutrient/sensory quality & $66 \%$ & 139 \\
Enhancing product's shelf life & $38 \%$ & 80 \\
Solution for safety problems & $24 \%$ & 51 \\
Cost-saving (energy, water) & $15 \%$ & 32 \\
Government/regulatory requirements & $15 \%$ & 31 \\
Collecting results for research & $12 \%$ & 25 \\
Convenience & $10 \%$ & 22 \\
Price (cheaper equipment) & $10 \%$ & 21 \\
Others & $5 \%$ & 11 \\
\hline
\end{tabular}

Non-thermal food production processes were adopted by corporations to protect the sensory qualities of the foods.

\section{Conclusion}

Traditional FP and storage methods, such as the use of additives and preservatives or heat processes like pasteurization, result in nutritional value loss, sensory changes, and negative health effects for consumers. Non-traditional processing and maintenance methods are rapidly growing in popularity today. They use a variety of food preservation techniques, including different thermal processes, chemical consumption, smoking, and irradiation. Food quality is maintained for various periods of time by using the gamma radiation method and storing products with optimal radiation, and spoilage factors are also controlled by controlling microorganisms. Fruit and vegetable ripening, aging, and germination are controlled by foods free of pathogenic bacteria, yeasts, moulds, and insects. The chemical composition of food changes to improve its quality, and after radiation, no toxins remain in the food. The best dose for most foods is around $4 \mathrm{kGy}$, and increasing the radiation dose for food may have negative consequences.

Because non-selective thermal processes are used in the disinfection process, they cause the cell walls of a wide range of microorganisms to be destroyed, thus targeting nutritional values and lowering product quality. Electromagnetic waves are increasingly being used in food storage to eliminate or (minimize) factors that reduce food quality due to thermal processes. In this paper, a new method for reducing microbial load was developed by combining the problems of processing thermal methods with electromagnetic knowledge. Using these waves in the Non-Thermal class to disinfect the path selectively can result in a variety of waves. The frequency range of microbial charge includes electromagnetism.

Extensive research has been done on non-thermal food storage methods to explore the possibility of using them as alternatives or complementary to conventional methods. Typically, most foods are heat-assisted at 60-100 degrees Celsius. They're being processed for a few seconds to a few minutes. A large amount of energy is transferred to the food during the thermal process. This energy can cause undesired reactions in food and cause undesirable changes or the formation of side compounds. For example, heat-treated milk may have a ripe taste which results in a loss of vitamins, essential nutrients, and flavor-producing substances. The use of non-thermal methods of food storage is expanding to eliminate (or minimize) factors that reduce the quality of food resulting from thermal processes. The temperature of the food during the non-thermal process is lower than the temperature of the food. They are commonly used in thermal processes so that the quality reduction resulting from the use of high temperatures is minimized in non-thermal processes, and vitamins, essential nutrients, and flavor enhancers are expected during non-thermal processes. The heat remains unchanged or is subject to minimal change. Furthermore, non-thermal processes require less energy than thermal processes. Food can be processed using non-thermal methods such as high hydrostatic pressure, pulsed electrical fields, intense light pulses, radiation, chemicals, biochemicals.

\section{References}

Afshari, R., \& Hosseini, H. (2014). Non-thermal plasma as a new food preservation method, its present and future prospect. Archives of Advances in Biosciences, 5(1)

Bhattacharjee, C., Saxena, V. K., \& Dutta, S. (2019). Novel thermal and non-thermal processing of watermelon juice. Trends in Food Science \& Technology, 93, 234-243. http://dx.doi.org/10.1016/j.tifs.2019.09.015.

Cebrián, G., Mañas, P., \& Condón, S. (2016). Comparative resistance of bacterial foodborne pathogens to non-thermal technologies for food preservation. Frontiers in Microbiology, 7, 734. http://dx.doi. org/10.3389/fmicb.2016.00734. PMid:27242749.

Considine, K. M., Kelly, A. L., Fitzgerald, G. F., Hill, C., \& Sleator, R. D. (2008). High-pressure processing-effects on microbial food safety and food quality. FEMS Microbiology Letters, 281(1), 1-9. http:// dx.doi.org/10.1111/j.1574-6968.2008.01084.x. PMid:18279335.

Corbo, M. R., Bevilacqua, A., Campaniello, D., D’Amato, D., Speranza, B., \& Sinigaglia, M. (2009). Prolonging microbial shelf life of foods through the use of natural compounds and non-thermal approaches-a review. International Journal of Food Science \& Technology, 44(2), 223-241. http://dx.doi.org/10.1111/j.1365-2621.2008.01883.x.

Cullen, P. J., Tiwari, B. K., \& Valdramidis, V. P. (2012). Status and trends of novel thermal and non-thermal technologies for fluid foods. In P.J. Cullen, B. K. Tiwari \& V. P. Valdramidis (Eds.), Novel thermal and non-thermal technologies for fluid foods (p. 1-6). Amsterdam: Elsevier. http://dx.doi.org/10.1016/B978-0-12-381470-8.00001-3.

Diehl, J. F. (2002). Food irradiation-past, present and future. Radiation Physics and Chemistry, 63(3-6), 211-215. http://dx.doi.org/10.1016/ S0969-806X(01)00622-3.

Gerlach, D., Alleborn, N., Baars, A., Delgado, A., Moritz, J., \& Knorr, D. (2008). Numerical simulations of pulsed electric fields for food preservation: a review. Innovative Food Science \& Emerging Technologies, 9(4), 408-417. http://dx.doi.org/10.1016/j.ifset.2008.02.001.

Giner, J., Gimeno, V., Barbosa-Cánovas, G. V., \& Martín, O. (2001). Effects of pulsed electric field processing on apple and pear polyphenoloxidases. Food Science \& Technology International, 7(4), 339-345. http://dx.doi.org/10.1106/MJ46-8J9U-1H11-T0ML.

González-Pérez, J. E., Ramírez-Corona, N., \& López-Malo, A. (2021). Mass transfer during osmotic dehydration of fruits and vegetables: process factors and non-thermal methods. Food Engineering Reviews, 13, 344-374.

Guillén, S., Marcén, M., Mañas, P., \& Cebrián, G. (2020). Differences in resistance to different environmental stresses and non-thermal 
food preservation technologies among Salmonella enterica subsp. Enterica strains. Food Research International, 132, 109042. http:// dx.doi.org/10.1016/j.foodres.2020.109042. PMid:32331679.

Hyun, J., \& Lee, S. (2020). Blue light-emitting diodes as eco-friendly non-thermal technology in food preservation. Trends in Food Science \& Technology, 105, 284-295. http://dx.doi.org/10.1016/j. tifs.2020.09.008.

Ihsanullah, I., \& Rashid, A. (2017). Current activities in food irradiation as a sanitary and phytosanitary treatment in the Asia and the Pacific Region and a comparison with advanced countries. Food Control, 72, 345-359. http://dx.doi.org/10.1016/j.foodcont.2016.03.011.

Indiarto, R., \& Qonit, M. A. H. (2020). A review of irradiation technologies on food and agricultural products. International Journal of Scientific \& Technology Research, 9(1), 4411-4414.

Jeyamkondan, S., Jayas, D. S., \& Holley, R. A. (1999). Pulsed electric field processing of foods: a review. Journal of Food Protection, 62(9), 1088-1096. http://dx.doi.org/10.4315/0362-028X-62.9.1088. PMid:10492486.

Jia, M., Zhang, Q. H., \& Min, D. B. (1999). Pulsed electric field processing effects on flavor compounds and microorganisms of orange juice. Food Chemistry, 65(4), 445-451. http://dx.doi.org/10.1016/S03088146(98)00186-1.

Knorr, D. (2003). Impact of non-thermal processing on plant metabolites. Journal of Food Engineering, 56(2-3), 131-134. http://dx.doi. org/10.1016/S0260-8774(02)00321-7.

Knorr, D., Ade-Omowaye, B. I. O., \& Heinz, V. (2002). Nutritional improvement of plant foods by non-thermal processing. The Proceedings of the Nutrition Society, 61(2), 311-318. http://dx.doi. org/10.1079/PNS2002162. PMid:12133214.

Lehmali, I. F., \& Jafari, M. A. (2019). Effect of different thermal and non-thermal processing methods on chemical composition, quality indicators and apparent nutrient digestibility of full-fat soybean. Brazilian Journal of Poultry Science, 21(4), eRBCA-2019-1099. http:// dx.doi.org/10.1590/1806-9061-2019-1099.

Lelieveld, H. L., Notermans, S., \& Haan, S. W. H. (2007). Food preservation by pulsed electric fields: from research to application. Amsterdam: Elsevier.

Lipiec, J., Janas, P., \& Barabasz, W. (2004). Effect of oscillating magnetic field pulses on the survival of selected microorganisms. International Agrophysics, 18(4)

Martins, C. P., Cavalcanti, R. N., Cardozo, T. S., Couto, S. M., Guimarães, J. T., Balthazar, C. F., Rocha, R. S., Pimentel, T. C., Freitas, M. Q., Raices, R. S. L., Silva, M. C., Esmerino, E. A., Granato, D., \& Cruz, A. G. (2021). Effects of microwave heating on the chemical composition and bioactivity of orange juice-milk beverages. Food Chemistry, 345, 128746. http://dx.doi.org/10.1016/j.foodchem.2020.128746. PMid:33307435.

Min, S., Jin, Z. T., Min, S. K., Yeom, H., \& Zhang, Q. H. (2003). Commercial-scale pulsed electric field processing of orange juice. Journal of Food Science, 68(4), 1265-1271. http://dx.doi. org/10.1111/j.1365-2621.2003.tb09637.x.

Molins, R. A. (2001). Food irradiation: principles and applications. New York: John Wiley \& Sons.

Moreira, S. A., Alexandre, E. M., Pintado, M., \& Saraiva, J. A. (2019). Effect of emergent non-thermal extraction technologies on bioactive individual compounds profile from different plant materials. Food Research International, 115, 177-190. http://dx.doi.org/10.1016/j. foodres.2018.08.046. PMid:30599930.

Morris, C., Brody, A. L., \& Wicker, L. (2007). Non-thermal food processing/preservation technologies: a review with packaging implications. Packaging Technology and Science: An International Journal, 20(4), 275-286. http://dx.doi.org/10.1002/pts.789.

Ohlsson, T., \& Bengtsson, N. (2002). Minimal processing of foods with non-thermal methods. Minimal Processing Technologies in the Food Industry, 34-60.

Osae, R., Essilfie, G., Alolga, R. N., Akaba, S., Song, X., Owusu-Ansah, P., \& Zhou, C. (2020). Application of non-thermal pretreatment techniques on agricultural products prior to drying: a review. Journal of the Science of Food and Agriculture, 100(6), 2585-2599. http:// dx.doi.org/10.1002/jsfa.10284. PMid:31975406.

Pal, M. (2017). Pulsed electric field processing: an emerging technology for food preservation. Journal of Excipients and Food Chemicals, 3(2), 2-3. http://dx.doi.org/10.4172/2472-0542.1000126.

Pereira, R. N., \& Vicente, A. A. (2010). Environmental impact of novel thermal and non-thermal technologies in food processing. Food Research International, 43(7), 1936-1943. http://dx.doi.org/10.1016/j. foodres.2009.09.013.

Pothakamury, U. R., Monsalve-Gonzalez, A., Barbosa-Cánovas, G. V., \& Swanson, B. G. (1995). Inactivation of Escherichia coli and Staphylococcus aureus in model foods by pulsed electric field technology. Food Research International, 28(2), 167-171. http:// dx.doi.org/10.1016/0963-9969(95)90801-G.

Purnell, G., James, C., \& James, S. J. (2017). The effects of applying oscillating magnetic fields during the freezing of apple and potato. Food and Bioprocess Technology, 10(12), 2113-2122. http://dx.doi. org/10.1007/s11947-017-1983-3.

Rifna, E. J., Singh, S. K., Chakraborty, S., \& Dwivedi, M. (2019). Effect of thermal and non-thermal techniques for microbial safety in food powder: recent advances. Food Research International, 126, 108654. http://dx.doi.org/10.1016/j.foodres.2019.108654. PMid:31732065.

Roberts, P. B. (2014). Food irradiation is safe: half a century of studies. Radiation Physics and Chemistry, 105, 78-82. http://dx.doi.org/10.1016/j. radphyschem.2014.05.016.

Rocha, R. S., Silva, R., Guimarães, J. T., Balthazar, C. F., Pimentel, T. C., Neto, R. P., Tavares, M. I. B., Esmerino, E. A., Freitas, M. Q., Cappato, L. P., Calvacanti, R. N., Rodrigues, F. N., Raices, R. S. L., Silva, M. C., \& Cruz, A. G. (2020). Possibilities for using ohmic heating in Minas Frescal cheese production. Food Research International, 131, 109027. http://dx.doi.org/10.1016/j.foodres.2020.109027. PMid:32247497.

Rodríguez, A. C., James, C., \& James, S. J. (2017). Effects of weak oscillating magnetic fields on the freezing of pork loin. Food and Bioprocess Technology, 10(9), 1615-1621. http://dx.doi.org/10.1007/ s11947-017-1931-2.

Schottroff, F., Fröhling, A., Zunabovic-Pichler, M., Krottenthaler, A., Schlüter, O., \& Jäger, H. (2018). Sublethal injury and viable but nonculturable (VBNC) state in microorganisms during preservation of food and biological materials by non-thermal processes. Frontiers in Microbiology, 9, 2773. http://dx.doi.org/10.3389/fmicb.2018.02773. PMid:30515140.

Shabbir, M. A., Ahmed, H., Maan, A. A., Rehman, A., Afraz, M. T., Iqbal, M. W., Khan, I. M., Amir, R. M., Ashraf, W., \& Khan, M. R. (2020). Effect of non-thermal processing techniques on pathogenic and spoilage microorganisms of milk and milk products. Food Science and Technology, 41(2), 279-294.

Silva, R., Rocha, R. S., Guimarães, J. T., Balthazar, C. F., Pimentel, T. C., Neto, R. P., Tavares, M. I. B., Esmerino, E. A., Duarte, M. C. K. H., Freitas, M. Q., Silva, P. H. F., Cappato, L. P., Raices, R. S. L., Silva, M. C., \& Cruz, A. G. (2020a). Advantages of using ohmic heating in Dulce de Leche manufacturing. Innovative Food Science \& Emerging Technologies, 65, 102475. http://dx.doi.org/10.1016/j. ifset.2020.102475. 
Silva, R., Rocha, R. S., Guimarães, J. T., Balthazar, C. F., Ramos, G. L. P., Scudino, H., Pimentel, T. C., Azevedo, E. M., Silva, M. C., Cavalcanti, R. N., Alvarenga, V. O., Duarte, M. C. K. H., Esmerino, E. A., Freitas, M. Q., \& Cruz, A. G. (2020b). Ohmic heating technology in dulce de leche: physical and thermal profile, microstructure, and modeling of crystal size growth. Food and Bioproducts Processing, 124, 278-286. http://dx.doi.org/10.1016/j.fbp.2020.09.001.

Stoica, M., Mihalcea, L., Borda, D., \& Alexe, P. (2013). Non-thermal novel food processing technologies. An overview. Journal of Agroalimentary Processes and Technologies, 19(2), 212-217.

Syed, Q. A., Ishaq, A., Rahman, U. U., Aslam, S., \& Shukat, R. (2017). Pulsed electric field technology in food preservation: a review. Journal of Nutritional Health \& Food Engineering, 6(6), 168-172.

Tewari, G., \& Juneja, V. (2008). Advances in thermal and non-thermal food preservation. New York: John Wiley \& Sons.

Tiwari, B. K., O'donnell, C. P., \& Cullen, P. J. (2009). Effect of non thermal processing technologies on the anthocyanin content of fruit juices. Trends in Food Science \& Technology, 20(3-4), 137-145. http://dx.doi.org/10.1016/j.tifs.2009.01.058.

Vega-Mercado, H., Martin-Belloso, O., Qin, B.-L., Chang, F. J., GóngoraNieto, M. M., Barbosa-Cánovas, G. V., \& Swanson, B. G. (1997).
Non-thermal food preservation: pulsed electric fields. Trends in Food Science \& Technology, 8(5), 151-157. http://dx.doi.org/10.1016/ S0924-2244(97)01016-9.

Wouters, P. C., Alvarez, I., \& Raso, J. (2001). Critical factors determining inactivation kinetics by pulsed electric field food processing. Trends in Food Science \& Technology, 12(3-4), 112-121. http://dx.doi. org/10.1016/S0924-2244(01)00067-X.

Zhang, H., \& Mittal, G. S. (2008). Effects of high-pressure processing (HPP) on bacterial spores: an overview. Food Reviews International, 24(3), 330-351. http://dx.doi.org/10.1080/87559120802089290.

Zhang, Z.-H., Wang, L.-H., Zeng, X.-A., Han, Z., \& Brennan, C. S. (2019). Non-thermal technologies and its current and future application in the food industry: a review. International Journal of Food Science \& Technology, 54(1), 1-13. http://dx.doi.org/10.1111/ijfs.13903.

Zhao, Y., de Alba, M., Sun, D., \& Tiwari, B. (2019). Principles and recent applications of novel non-thermal processing technologies for the fish industry-a review. Critical Reviews in Food Science and Nutrition, 59(5), 728-742. http://dx.doi.org/10.1080/10408398.201 8.1495613. PMid:30580554. 